\title{
Eosinophilic Folliculitis in a Dog
}

\author{
Gabriel Utida Eguchi ${ }^{1}$, Alda Izabel de Souza $\mathbb{D}^{2}$, Veronica Jorge Babo-Terra $\mathbb{D}^{2}$, \\ Luiz Henrique de Araújo Machado ${ }^{3} \&$ Mariana Isa Poci Palumbo ${ }_{i}^{2}$
}

\begin{abstract}
Background: Canine eosinophilic folliculitis is a dermatological disease of acute onset with development of erosive to ulcerative papular lesions, especially on the nasal bridge, that may cause severe skin abnormalities leading to discomfort and pain to the patient. The aim of this report was to characterize a case of a canine eosinophilic folliculitis with papular, ulcerative and crusting dermatitis on the nasal bridge, papules on eyelid and pinna, with confirmed diagnosis based on aspiration cytology, history and response to immunosuppressive therapy with glucocorticoid.

Case: An 1-year-old intact Daschund was attended showing an acute onset (over $4 \mathrm{~h}$ ) of generalized urticarial reaction and nonpruriginous lesion at the muzzle with mild serosanguineous exudate, which persisted for $96 \mathrm{~h}$ when the dog was evaluated. It was observed a papular and ulcerative dermatitis with serosanguineous exudate and hematic crusts at nasal bridge, papules measuring $2 \mathrm{~mm}$ in diameter in the medial and lateral canthus of the left eyelid, ulcerative papule with hematic crust in the border of left ear pinna, multifocal papules on the skin, dyskeratosis and generalized hair loss. The patient was anesthetized for blood sampling (CBC and serum biochemistry), lesions fine-needle aspiration, scraping and imprint for cytological examination, bacterial culture and nasal turbinates radiography. Fragments for histopathological evaluation were also collected. Erythrogram and platelet evaluation were unremarkable. Leukogram revealed leukocytosis (neutrophilia, lymphocytosis, monocytosis and eosinophilia). Serum biochemistry revealed hyperalbuminemia and discrete hyperproteinemia; values of alanine aminotransferase, creatinine and globulins were within normal range. In cytological examination, intense cellularity was observed with predominance of eosinophils (60\%), neutrophils (35\%), macrophages performing cytophagocytosis (5\%) and degenerated cells. There was no bacterial growth within $48 \mathrm{~h}$ after incubation of nasal bridge lesion swab. There were no abnormalities identified at radiographic evaluation of nasal turbinates. As the patient was already with antibiotic therapy and steroidal anti-inflammatory, it was opted to maintain it, since interruption between the day of examination and laboratory results could cause more prejudice than benefit, corticosteroid dose, however, was readjusted (prednisone $2 \mathrm{mg} / \mathrm{kg} /$ per os/every $24 \mathrm{~h}$ ). After 1 week of treatment the owner reported significant improvement of clinical signs without any further complaint.

Discussion: Typically, type I hypersensitivity reactions such as insect bites do not exceed clinical signs of erythema, local edema and pruritus, with spontaneous remission of clinical signs within few hours after exposure to the antigen. Eosinophilic folliculitis, however, may cause more severe clinical alterations, such as pain, apathy and hyporexia. Nasal bridge is the predominant site described to be affected in cases of eosinophilic folliculitis, being auricular pinna, thorax and limbs considered atypical presentations which can delay proper diagnosis, since in endemic regions for diseases such as visceral leishmaniasis, infectious etiology may be listed first. Differential diagnosis also includes superficial pyoderma, juvenile cellulitis, pemphigus foliaceus and pharmacodermia. The case described in this report emphasize the importance of an accurate diagnosis as well as an early and adequate treatment in order to promote satisfactory response. Also, highlights inadequate use of antimicrobials as a direct consequence of lack of laboratorial investigation.
\end{abstract}

Keywords: skin, eosinophilia, furunculosis, dermatitis, insects. 


\section{INTRODUCTION}

Eosinophilic folliculitis or canine eosinophilic furunculosis $(\mathrm{CEF})$ is an acute dermatological condition associated with a hypersensitivity reaction to arthropods (mosquitoes, bees or spiders) and usually manifests with lesions in the nasal bridge (erythema, papules, crusts, ulcers), however, it can affect regions like periocular [8], axillary, limbs, chest and lips [6].

Physical examination and anamnesis information are usually sufficient to confirm the disease, however, cytological and histopathological examination are indicated for definitive diagnosis [3].

The objective of this report was to characterize the clinical presentation, evolution and response to treatment in a canine patient with CEF, detailing complementary exams used for diagnostic confirmation. Also, it highlights inadequate use of antimicrobials without appropriate confirmation of bacterial involvement.

\section{CASE}

A 1-year-old canine male patient, Daschund, was attended with history of generalized urticarial reaction and nonpruritic lesions in the muzzle with mild serosanguinolent exudate.

The condition had an acute onset with dermatological signs progressing over a $4 \mathrm{~h}$ period, lasting for $96 \mathrm{~h}$, time of the consultation. Sensitivity and discomfort with worsening of clinical signs was also reported. The patient lived in a rural environment, with a canine cohabitant without similar signs and had sporadic contact with stray felines from neighboring properties. Initially, treatment with prednisone ${ }^{1}[0.6$ $\mathrm{mg} / \mathrm{kg} /$ per os/every $24 \mathrm{~h}$ ] and cephalexin ${ }^{2}$ [18 mg/kg/ per os/every $12 \mathrm{~h}$ ] and after $72 \mathrm{~h}$, no improvement of clinical signs was observed.

On physical examination, it was identified papular and ulcerative dermatitis with serosanguinolent exudate and hematic crusts in the nasal bridge, papules measuring $2 \mathrm{~mm}$ in diameter in the nasal and temporal cantus of the left eyelid (Figure 1A), ulcerative papule with hematic crust on the edge of the left auricular pinna (Figure 1B) and multifocal papules and dyskeratosis with generalized hair loss.

After the patient was anesthetized with propo$\mathrm{fol}^{3}$ [4 $\mathrm{mg} / \mathrm{kg} /$ intravenously] associated with midazo$\operatorname{lam}^{3}[0.2 \mathrm{mg} / \mathrm{kg} /$ intravenously], blood samples were collected for $\mathrm{CBC}$ and serum biochemistry. Lesion samples were acquired with sterile cotton swabs and stored in Stuart media ${ }^{4}$ for transport and bacterial culture. Scraping, imprinting and swab scarification were made for cytological examination. Finally, nasal turbinates radiography was performed.

Two fragments were collected for histopathological analysis, however, the samples were considered insufficient for processing. Erythrogram and platelet values were within reference range. Leukogram revealed leukocytosis $21,800 \mathrm{~mm}^{3}$ (reference 6,000 to $17,000 \mathrm{~mm}^{3}$ ), neutrophilia $13,952 \mathrm{~mm}^{3}$ (reference 3,000 to $11,500 \mathrm{~mm}^{3}$ ), lymphocytosis $5,014 \mathrm{~mm}^{3}$ (reference 1,000 to $4,800 \mathrm{~mm}^{3}$ ), monocytosis $872 \mathrm{~mm}^{3}$ (reference 0 to $850 \mathrm{~mm}^{3}$ ) and eosinophilia $1,962 \mathrm{~mm}^{3}$ (reference 0 to $1,500 \mathrm{~mm}^{3}$ ). Altered serum biochemistry included hyperalbuminemia $3.7 \mathrm{~g} / \mathrm{dL}$ (reference 2.6 to $3.3 \mathrm{~g} / \mathrm{dL}$ ) and mild hyperproteinemia $7.2 \mathrm{~g} /$ $\mathrm{dL}$; alanine aminotransferase, creatinine and globulin values were within normal range.

In cytological examination, there was intense cellularity with predominance of eosinophils $(60 \%)$, neutrophils (35\%), mild presence of macrophages performing cytophagocytosis $(5 \%)$ and degenerated cells (Figure 1C). There was no bacterial growth in a $48 \mathrm{~h}$ period of incubation on blood agar plate of nasal skin swabs. No radiographic changes were identified for nasal turbinates.

Considering the interval between sampling and test results, it was preferred to continue the treatment with antibiotic therapy, once cytology and bacterial culture did not confirm bacterial involvement, cephalexin was discontinued. The steroidal anti-inflammatory treatment with prednisone was readjusted [to $2 \mathrm{mg} / \mathrm{kg}$ / per os/every $24 \mathrm{~h} /$ for 7 days] with gradual reduction after 20 days. After one week of treatment, the owner reported significant improvement of clinical signs without any other complaints (Figure 1D). After 75 days there was complete remission of the initial clinical signs.

\section{DISCUSSION}

Commonly, type-I hypersensitivity reactions such as insect bites, do not go beyond clinical signs of local erythema, edema and pruritus, with remission of clinical signs within few hours after exposure to the antigen [1]. However, CEF can cause more serious clinical changes, and, as in the case described, there are reports of patients with local painful sensitivity (nasal bridge), including complaints of apathy and hyporexia $[4,7,8]$. 


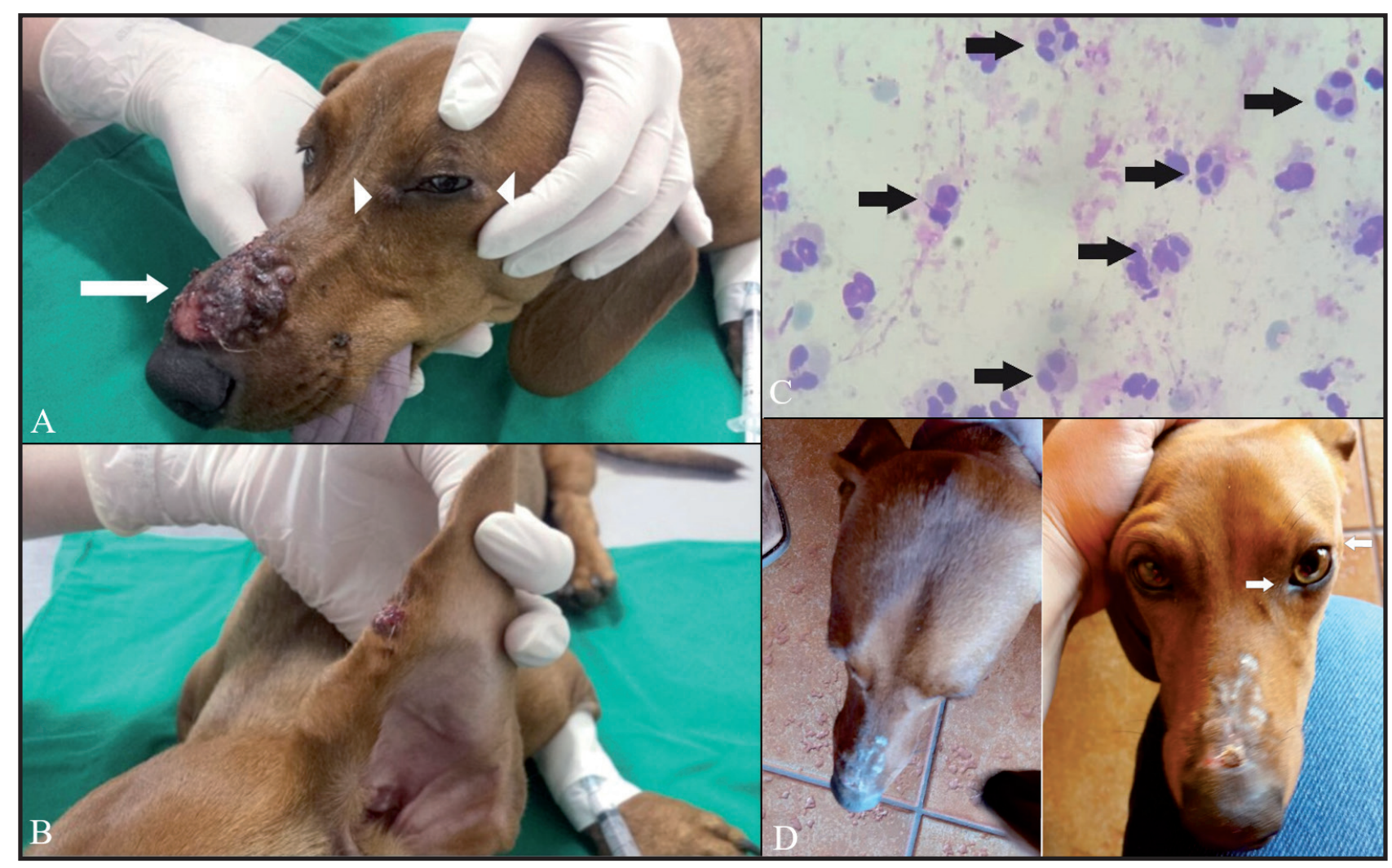

Figure 1. A- Papular lesion with extensive ulcer, presence of serosanguinolent exudate and hematic crusts in the nasal bridge (arrow) of a canine patient with eosinophilic folliculitis. Note papules of $2 \mathrm{~mm}$ in diameter in nasal and temporal canthus of left eyelid (arrow heads). B- Papular lesion with ulcer and hematic crust in the edge of left auricular pinna. C- Cytology of nasal bridge lesion (400x). Note marked presence of eosinophils (black arrows). D- Patient after seven days of treatment. Note complete remission of eyelid's papules (white arrows).

Nasal bridge is the predominant site of injury described in cases of CEF $[4,7,10]$, with atypical presentations including auricular pinna, chest and limbs [7,11]. Clinical features of unusual signs can hinder diagnosis, especially in endemic regions for diseases such as visceral leishmaniasis, which could be the primary differential, therefore delaying initiation of appropriate therapy.

Bacterial skin diseases such as superficial pyoderma is also a diagnostic differential and can manifest as papules, pustules, crusts, plaques and areas of alopecia and erythema [8]. As in any case of dermatitis with bacterial involvement, the clinical presentation can be acute and be similar in evolution and clinical manifestation as $\mathrm{CEF}$, however, most of them regress with antimicrobial therapy [5]. In addition, no bacteria were observed in lesion cytology and culture was negative.

Juvenile cellulitis, another skin disease included in the differential, commonly manifests in puppies between five weeks to four months of age, being more common in Daschunds, Golden Retrievers and Labrador Retrievers, with clinical signs that vary between papular, pustular, vesicular lesions and alopecic disease most prevalent on lips, snout and eyelids [9]. Unlike
$\mathrm{CEF}$, the inflammatory cell pattern characteristic of juvenile cellulitis is a pyogranuloma, with predominance of macrophages [9]. Despite the similarity regarding clinical signs of juvenile cellulite and CEF, the regions affected in this case do not match, as well as age and mainly, cytological difference, being unlikely a juvenile cellulitis diagnosis in this case.

According to Balda et al. [2], pemphigus foliaceus can cause secondary lesions such as erosions and crusts in nasal bridge and ear buds that can later evolve to mucocutaneous involvement and generalized lesions. Cytology with pustular content (very common in pemphigus foliaceus) reveals acantholytic cells [2], unlike cases of CEF in which the lesions are usually focal with a cytological pattern of predominance of eosinophils [6].

Adverse reactions to medications should also be considered, since pharmacodermias, although uncommon, can be manifested by individual hypersensitivity reactions, varying widely in terms of clinical presentation as well as time of onset of clinical signs [12]. The possibility of pharmacodermia was ruled out by excluding any possibility of contact with drugs and/ or chemical substances from anamnesis. 
Thus, exclusion of other differentials to an appropriate and adequate prognosis is crucial. Mostly important, indiscriminate use of antimicrobials not only seems a self-medication issue among general population, but it also appears to be a recklessness present among health care professionals, given the fact that in many cases it is formally prescribed. Despite gross appearance of lesions associated with CEF mislead the clinician to presume bacterial involvement, that is not commonly true [7]. As the patient of this report already used cephalexin for three consecutive days since time of swab sampling, there is a probability of absence of bacteria in response to that treatment. Nevertheless, it is not recommended such approach for lesions that classically are known to be aseptic, specially when no purulent discharge is present or cytology don't find bacteria.
Considering clinical evolution, history and complementary exams in this case, the diagnosis was of CEF. The importance of a wide approach in the differential of dermatological diseases is emphasized, due to the variability and overlap of clinical signs, since accurate diagnosis helps in the establishment of an early therapy, with respect to doses and frequencies recommended for the species and disease.

\section{MANUFACTURERS}

${ }^{1}$ Ouro Fino Saúde Animal. Cravinhos, SP, Brazil.

${ }^{2}$ Mundo Animal. Pindamonhangaba, SP, Brazil.

${ }^{3}$ Cristália Produtos Químicos Farmacêuticos Ltda. Itapira, SP, Brazil.

${ }^{4}$ Kasvi Produtos para Laboratórios Ltda. São José dos Pinhais, PR, Brazil.

Declaration of interest. The authors report no conflicts of interest. The authors alone are responsible for the content and writing of the paper.

\section{REFERENCES}

1 Abbas A.K., Lichtman A.H. \& Pillai S. 2012. Respostas Imunes Dependentes de IgE e Doenças Alérgicas. In: Imunologia Celular e Molecular. 7.ed. Rio de Janeiro: Elsevier, pp.425-444.

2 Balda A.C., Ikeda M.O., Larsson-Junior C.E., Michalany N.S. \& Larsson C.E. 2008. Pênfigo foliáceo canino: estudo retrospectivo de 43 casos clínicos e terapia (2000-2005). Pesquisa Veterinária Brasileira. 28: 387-392.

3 Bloom P.B. 2006. Canine and Feline Eosinophilic Skin Diseases. Veterinary Clinics: Small Animal Practice. 36: 141-160.

4 Curtis C.F., Bond R., Blunden A.S., Thomson D.G., Mcneil P.E. \& Whitbread T.W. 1995. Canine eosinophilic folliculitis and furunculosis in three cases. Journal of Small Animal Practice. 36: 119-123.

5 Gortel K. 2013. Recognizing Pyoderma: More Difficult than it May Seem. Veterinary Clinics of North America: Small Animal Practice. 43: 1-18.

6 Gross T.L., Ihrke P.J., Walder E.J. \& Affolter V.K. 2005. Skin Diseases of the Dog and Cat: Clinical and Histopathological Diagnosis. 2nd edn. Oxford: Blackwell Publishing, pp.405-533.

7 Pereira A.V., Gremião I.D.F., Silva D.A., Machado A.C.S. \& Pereira S.A. 2012. Furunculose eosinofílica canina. Acta Scientiae Veterinariae. 40: 1023. 5p.

8 Salzo P.S. 2016. Hipersensibilidade a insetos e aracnídeos. In: Tratado de Medicina Externa: Dermatologia Veterinária. São Caetano do Sul: Interbook Editorial Ltda., pp.544-545.

9 Scott D.W. \& Miller W.H. 2007. Juvenile cellulitis in dogs: a retrospective study of 18 cases (1976-2005). The Japanese Journal of Veterinary Dermatology. 13: 71-79.

10 Soyer C. 2006. Furonculose éosinophilique chez un golden retriever. Le Point Vétérinaire. 269: 60-63.

11 Van-Poucke S. 2000. What is your diagnosis - canine eosinophilic furunculosis. Journal of Small Animal Practice. 41: 485-524.

12 Voie K.L., Campbell K.L. \& Lavergne S.N. 2012. Drug Hipersensitivity Reactions Targeting the Skin in Dogs and Cats. Journal of Veterinary Internal Medicine. 26: 863-874. 